\title{
Azetidinium Lead Halide Ruddlesden-Popper Phases
}

\author{
Jiyu Tian ${ }^{1,2}$, Eli Zysman-Colman ${ }^{2, *(D)}$ and Finlay D. Morrison $1, *$ (D) \\ 1 EaStCHEM School of Chemistry, University of St Andrews, St Andrews KY16 9ST, UK; \\ jt201@st-andrews.ac.uk \\ 2 Organic Semiconductor Centre, EaStCHEM School of Chemistry, University of St Andrews, \\ St Andrews KY16 9ST, UK \\ * Correspondence: eli.zysman-colman@st-andrews.ac.uk (E.Z.-C.); finlay.morrison@st-andrews.ac.uk (F.D.M.)
}

check for updates

Citation: Tian, J.; Zysman-Colman, E.; Morrison, F.D. Azetidinium Lead Halide Ruddlesden-Popper Phases. Molecules 2021, 26, 6474. https:// doi.org/10.3390/molecules26216474

Academic Editors: William T.

A. Harrison, R. Alan Aitken and Paul Waddell

Received: 29 September 2021

Accepted: 21 October 2021

Published: 27 October 2021

Publisher's Note: MDPI stays neutral with regard to jurisdictional claims in published maps and institutional affiliations.

Copyright: (c) 2021 by the authors. Licensee MDPI, Basel, Switzerland. This article is an open access article distributed under the terms and conditions of the Creative Commons Attribution (CC BY) license (https:/ / creativecommons.org/licenses/by/ $4.0 /)$.

\begin{abstract}
A family of Ruddlesden-Popper $(n=1)$ layered perovskite-related phases, $\mathrm{Az}_{2} \mathrm{PbCl}_{x} \mathrm{Br}_{4-x}$ with composition $0 \leq x \leq 4$ were obtained using mechanosynthesis. These compounds are isostructural with $\mathrm{K}_{2} \mathrm{NiF}_{4}$ and therefore adopt the idealised $n=1$ Ruddlesden-Popper structure. A linear variation in unit cell volume as a function of anion average radius is observed. A tunable bandgap is achieved, ranging from 2.81 to $3.43 \mathrm{eV}$, and the bandgap varies in a second-order polynomial relationship with the halide composition.
\end{abstract}

Keywords: layered perovskite; bandgap tuning; azetidinium; Ruddlesden-Popper; structure-property relations

\section{Introduction}

Ruddlesden-Popper (R-P) phases are composed of layered perovskite structures with alternating layers of $\mathrm{AMX}_{3}$ perovskite and $\mathrm{AX}$ rock salt along the $c$-axis. They are described by the general formula $\mathrm{A}_{n+1} \mathrm{M}_{n} \mathrm{X}_{3 n+1}$ (or $\mathrm{A}_{2}{ }_{2} \mathrm{~A}_{n-1}{ }_{n-1} \mathrm{M}_{n} \mathrm{X}_{3 n+1}$ in the case of two distinct A-cations), where $n$ is a positive integer representing the number of perovskite layers that are separated by additional 'A-cation excess' rock-salt layers [1,2]. Importantly, the intergrowth rock salt layer means that the octahedra in the perovskite layers are aligned in the successive layers. In 1955, Balz and Plieth reported the first R-P phase layered structure $\mathrm{K}_{2} \mathrm{NiF}_{4}(n=1)$ [3]. In 1957, Ruddlesden and Popper reported a series of layered structures in oxides, such as $\mathrm{Sr}_{2} \mathrm{TiO}_{4}$ and $\mathrm{Ca}_{2} \mathrm{TiO}_{4}$ [4]. Nowadays, the R-P phase is more commonly used to represent this type of layered perovskite structure and, increasingly, in organic-inorganic hybrid perovskites (OIHPs). Several families of layered OIHPs containing alternating layers of $\mathrm{AMX}_{3}$ perovskite and organic cations with structures similar to $\mathrm{R}-\mathrm{P}$ phases have been reported. Such examples of layered OIHPs include $\mathrm{BA}_{2} \mathrm{PbI}_{4}\left(\mathrm{BA}=\mathrm{C}_{4} \mathrm{H}_{9} \mathrm{NH}_{3}{ }^{+}\right)$[5] and $\mathrm{PEA}_{2} \mathrm{PbX}_{4}\left(\mathrm{PEA}=\mathrm{C}_{8} \mathrm{H}_{12} \mathrm{~N}^{+}, \mathrm{X}=\mathrm{Cl}, \mathrm{Br}, \mathrm{I}\right),[6,7]$ in which the organic cations are too big to be accommodated in the cuboctahedral cavities of the $3 \mathrm{D} \mathrm{MX}_{6}$ framework. Without the constraint of the size of the cuboctahedral cavities, a wider range of organic A-cations would be available for layered phases. In addition, by mixing large ( $\left.\mathrm{A}^{\prime}\right)$ organic cations, such as those mentioned above, and small organic cations such as methylammonium $\left(\mathrm{A}^{\prime \prime}=\mathrm{MA}\right)$, organic-inorganic hybrid materials with the general formula $\mathrm{A}_{2}^{\prime} \mathrm{A}^{\prime \prime}{ }_{n-1} \mathrm{M}_{n} \mathrm{X}_{3 n+1}$ can be prepared $[5,8]$. They show good bandgap tunability by modifying the number of layers $(n)$ of $\mathrm{A}^{\prime \prime} \mathrm{PbX}_{3}$. Stoumpos et al. [5] reported orthorhombic crystal structures of $\mathrm{BA}_{2} \mathrm{MA}_{n-1} \mathrm{~Pb}_{n} \mathrm{X}_{3 n+1}(\mathrm{X}=\mathrm{Br}, \mathrm{I})$ with bandgaps changing progressively from $2.43 \mathrm{eV}(n=1)$ to $1.50 \mathrm{eV}(n=\infty)$, with intermediate values of $2.17 \mathrm{eV}(n=2), 2.03 \mathrm{eV}(n=3)$ and $1.91 \mathrm{eV}$ $(n=4)$. The thickness of the perovskite layer, $n$, in $(\mathrm{BA})_{2}(\mathrm{MA})_{n-1} \mathrm{~Pb}_{n} \mathrm{I}_{3 n+1}$ can be reasonably controlled by modifying the ratio of BA/MA cations in the precursor solutions. However, many so-called R-P phases reported in such compounds often do not have the required rock salt-structured interlayer between the $2 \mathrm{D}$ perovskite layers, resulting in an offset in the alignment of the perovskite blocks in successive layers. Such examples, therefore, do not conform to the definition of an R-P phase and are more correctly termed R-P-like 
OIHPs. Such R-P-like layered OIHPs have demonstrated higher stability when exposed to light, humidity and heat stress compared to 3D perovskite analogues, which are prone to unwanted phase transition under these test conditions $[9,10]$. For example, Ren et al. reported an R-P-like OIHPs solar cell material with general formula (MTEA) ${ }_{2}(\mathrm{MA})_{4} \mathrm{~Pb}_{5} \mathrm{I}_{16}$ $(n=5)$ which achieved a power conversion efficiency up to $17.8 \%$ [11]. Their cells retained over $85 \%$ of the initial efficiency after $1000 \mathrm{~h}$ operation time.

Azetidinium $\left(\mathrm{Az}^{+},\left(\mathrm{CH}_{2}\right)_{3} \mathrm{NH}_{3}{ }^{+}\right)$is a four-membered ring ammonium cation. In our previous study on mixed halide azetidinium lead perovskites, $\mathrm{AzPbBr}_{3-x} \mathrm{X}_{x}(\mathrm{X}=\mathrm{Cl}$ or I), the structure progresses from $6 \mathrm{H}$ to $4 \mathrm{H}$ to $9 \mathrm{R}$ perovskite polytypes with varying halide composition from $\mathrm{Cl}^{-}$to $\mathrm{Br}^{-}$to I- [12]. The fact that $\mathrm{AzPbX}_{3}(\mathrm{X}=\mathrm{Cl}$ or $\mathrm{Br})$ forms a hexagonal perovskite rather than a cubic (3C) perovskite led to our study on mix-cation solid solutions of the form $\mathrm{AzA}^{\prime \prime} \mathrm{PbBr}_{3}, \mathrm{~A}^{\prime \prime}=\mathrm{MA}^{+}$or $\mathrm{FA}^{+}\left(\mathrm{FA}^{+}=\right.$formamidinium). Such systems show only partial solid solutions and phase separation of the hexagonal and cubic forms; the extent of solid solution formation also depends on the synthesis route [13]. These studies also suggest that the cation radius of $\mathrm{Az}^{+}$is $\sim 310 \mathrm{pm}$, which is larger than the calculated cation radius of $\mathrm{Az}, r_{\mathrm{Az}}=250 \mathrm{pm}$ (for comparison the reported radii for $\mathrm{FA}^{+}$and $\mathrm{MA}^{+}$are $r_{\mathrm{FA}}=253 \mathrm{pm}, r_{\mathrm{MA}}=217 \mathrm{pm}$ [14], respectively). $\mathrm{MA}^{+}$and $\mathrm{FA}^{+}$are commonly used as A-site cations in OIHPs, and that adopt (pseudo-) cubic perovskite structures [15,16]. With our cation radius estimation that $\mathrm{Az}^{+}$is larger than $\mathrm{MA}^{+}$and $\mathrm{FA}^{+}, \mathrm{Az}_{2} \mathrm{PbX}_{4}(\mathrm{X}=\mathrm{Cl}$, $\mathrm{Br}$ ) are found to adopt a $n=1 \mathrm{R}-\mathrm{P}$ phase structure. The fact that $\mathrm{Az}^{+}$can form a layered structure indicates that our estimation of its cation radius is more accurate than that from the computational calculation $[13,14]$. Furthermore, a family of mixed halide R-P phases, $\mathrm{Az}_{2} \mathrm{PbCl}_{x} \mathrm{Br}_{4-x}$ with composition $0 \leq x \leq 4$ were prepared by mechanosynthesis and their structures and optical properties were analysed by powder X-ray diffraction (PXRD) and absorption spectroscopy, respectively. A linear variation in unit cell volume as a function of anion average radius is observed. The band gap was found to range from 2.81 to $3.43 \mathrm{eV}$, which varies as a second-order polynomial relationship with the halide composition.

\section{Method}

$\mathrm{PbBr}_{2}(98 \%)$ and $\mathrm{PbCl}_{2}(98 \%)$ were purchased from Alfa Aesar. Hydrobromic acid in water $(48 \%)$ and $\mathrm{AzCl}(95 \%)$ were purchased from Fluorochem. All other reagents and solvents were obtained from commercial sources and used as received. AzBr were synthesised according to our previous study [17].

Preparation of $\mathrm{Az}_{2} \mathrm{PbCl}_{x} \mathrm{Br}_{4-x}$ solid solutions with $0 \leq x \leq 4$ (in $x=0.67$ increments) was carried out by mechanosynthesis. Appropriate molar ratios of dry $\mathrm{AzX}$ and $\mathrm{PbX}$ ( $\mathrm{AzX}: \mathrm{PbX}_{2}=2: 1, \mathrm{X}=\mathrm{Cl}$ or $\mathrm{Br}$ ) were ground together in a Fritsch Pulverisette planetary ball mill at $600 \mathrm{rpm}$ for $1 \mathrm{~h}$ using $60 \mathrm{~cm}^{3}$ Teflon pots and high-wear-resistant zirconia media (nine $10 \mathrm{~mm}$ diameter spheres). $\mathrm{Az}_{2} \mathrm{PbBr}_{4}$ samples could also be obtained by hand grinding $\mathrm{AzBr}$ and $\mathrm{PbBr}_{2}$ in an agate mortar and pestle for $25 \mathrm{~min}$.

PXRD was carried out using a PANalytical Empyrean diffractometer with $\mathrm{Cu} \mathrm{K}_{\alpha 1}$ $(\lambda=1.5406 \AA)$. Rietveld refinements of PXRD data using GSAS [18] were used to confirm phase formation and for the determination of lattice parameters.

Optical properties were determined from solid-state absorption spectra recorded using a Shimadzu UV-2600 spectrophotometer and bandgaps were calculated by plotting $(\alpha h v)^{2}\left(\mathrm{~cm}^{-1} \cdot \mathrm{eV}\right)^{2}$ with $h v(\mathrm{eV})$ according to the Tauc method, in which $\alpha, h$ and $v$ stand for absorbance, Planck's constant and incident light frequency.

\section{Results}

The PXRD data for $\mathrm{Az}_{2} \mathrm{PbCl}_{x} \mathrm{Br}_{4-x}$ with compositions ranging from $0 \leq x \leq 4$ were prepared by mechanosynthesis and are shown in Figure $1 \mathrm{~b}$. The structures of these samples were determined to be R-P $n=1$ phase in the $I 4 / \mathrm{mmm}$ space group (Figure 1a). The theoretical diffraction pattern of the tetragonal $\mathrm{R}-\mathrm{P}$ phase is shown in Figure S1. Characteristic peaks of the R-P phase show systematic peak shifts to higher $2 \theta$ angle from $\mathrm{Az}_{2} \mathrm{PbBr}_{4}$ to $\mathrm{Az}_{2} \mathrm{PbCl}_{4}$, which indicate the lattice parameters decreased with more $\mathrm{Cl}$ content in the 
solid solution. The $\mathrm{Az}^{+}$cations, which are represented as solid spheres situated at the centre of electron density, form rock salt layers with the $\mathrm{X}^{-}$anions. Synthesis from solution is preferred when manufacturing devices because solutions can be easily processed into thin films by spin-coating and blade-coating methods compared to bulk powder [19]. Thus, precipitation synthesis of $\mathrm{Az}_{2} \mathrm{PbX}_{4}(\mathrm{X}=\mathrm{Cl}, \mathrm{Br}$ ) were also attempted (synthetic details included in the supporting information) and their PXRD data are shown in Figure S2. Although the precipitated samples contain additional phase(s) associated with additional peaks (e.g., at $6^{\circ}$ and $11^{\circ}$ ) and have yet to be assigned to a structure. Ganguli [20] reported an empirical prediction that possible R-P phase structures are associated with a ratio of A-site and metal cation radii $\left(r_{\mathrm{A}} / r_{\mathrm{M}}\right)$ in the range of 1.7 to 2.4. As discussed in our previous study [12], our estimation of the cation radius of $\mathrm{Az}^{+}(\sim 310 \mathrm{pm})$ differs from that calculated (250 pm) [14]. The $r_{\mathrm{Az}} / r_{\mathrm{Pb}}$ calculated using our estimated radius is 2.60 , while that using the literature value [14] is 2.10 .

a)

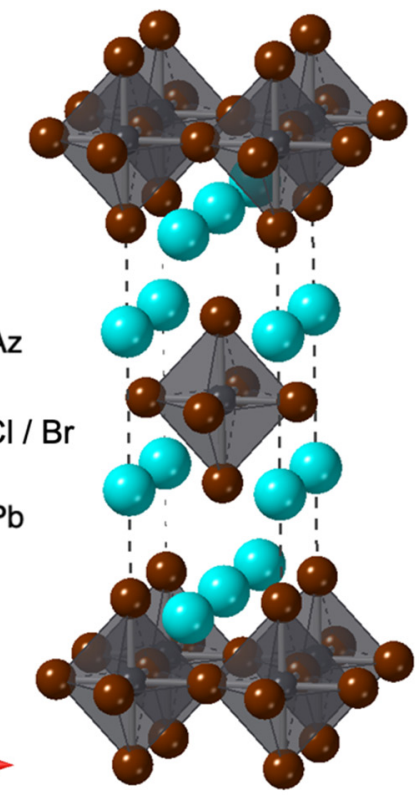

b)

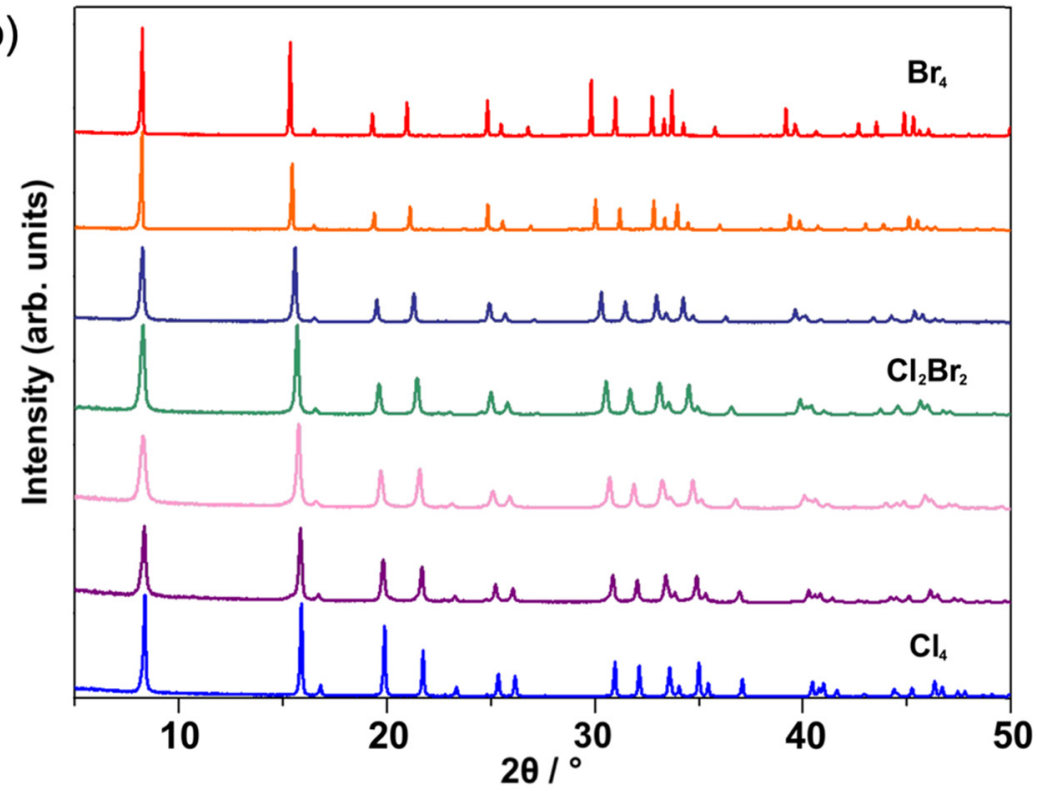

Figure 1. (a) $n=1$ Ruddlesden-Popper (R-P) phase of $\mathrm{Az}_{2} \mathrm{PbX}_{4}(\mathrm{X}=\mathrm{Cl}, \mathrm{Br})$ showing alternating $\mathrm{AzPbX}$ perovskite and AzX rock salt layers along the $c$-axis, (b) PXRD data of mix-halide layered R-P phases: $\mathrm{Az}_{2} \mathrm{PbCl}_{x} \mathrm{Br}_{4-x}$ with composition $0 \leq x \leq 4$ prepared by mechanosynthesis.

Unfortunately, our attempts to synthesise single-phase $\mathrm{Az}_{2} \mathrm{PbI}_{4}$ were unsuccessful. The PXRD of mechanosynthesised $\mathrm{Az}_{2} \mathrm{PbI}_{4}$ is shown in Figure $\mathrm{S} 3$. In addition to the R-P phase, there are evident amounts of $9 \mathrm{R} \mathrm{AzPbI}_{3}$ phase [12,21] and the relative intensity of this phase increased with increased ball mill grinding time (1 to $3 \mathrm{~h}$ ). PXRD of the $\mathrm{Az}_{2} \mathrm{PbI}_{4}$ sample obtained from a hand grinding synthesis showed that this method can increase the proportion of R-P phase in the samples, evidenced by the increased relative intensity of peaks associated with the R-P phase, but the presence of the $9 \mathrm{R}$ phase persisted across all samples. These results indicate that the $9 R$ phase is the more stable phase compared to the R-P phase for the iodide analogue It is likely that the activation energy for the transformation of azetidinium lead iodide from a layered phase to the $9 \mathrm{R}$ phase is low.

For simplicity, Rietveld refinements were carried out by replacing the organic $\mathrm{Az}^{+}$ cations with $\mathrm{Mn}^{2+}$, as they have similar electron densities. Figure 2 shows an example of the PXRD data refinement of $\mathrm{Az}_{2} \mathrm{PbX}_{4}(\mathrm{X}=\mathrm{Cl}, \mathrm{Br})$ samples obtained from the ball mill mechanosynthesis. The refined lattice parameters of $\mathrm{Az}_{2} \mathrm{PbBr}_{4}$ are $a=5.993(6) \AA$ and $c=21.501(1) \AA$, with goodness-of-fit parameters $\chi^{2}=10.21$ and $w R_{p}=0.115$, while those of $\mathrm{Az}_{2} \mathrm{PbCl}_{4}$ are $a=5.765(0) \AA$ and $c=21.027(2) \AA$, with goodness-of-fit parameters $\chi^{2}=7.20$ and $w R_{p}=0.102$. The difference between the organic moieties and $\mathrm{Mn}^{2+}$, which is associated with their actual atomic position and thermal motion, is one possible reason 
for such high $\chi^{2}$ values for both refinements and may be responsible for the differences in the peak shape and intensities shown. Single crystal diffraction analysis is required for detailed structural analysis, including accurate atoms positions (particularly of the $\mathrm{Az}^{+}$cation), however, this would require preparation of sufficiently large single crystals which are challenging by this mechanosynthesis route. Nevertheless, it is clear from the rudimentary Rietveld analysis of the PXRD data that all peaks are accounted for and that the PXRD unambiguously show the formation of $n=1 \mathrm{R}-\mathrm{P}$ materials. In addition, as the peaks positions can be determined accurately the unit cell dimensions are reliable.

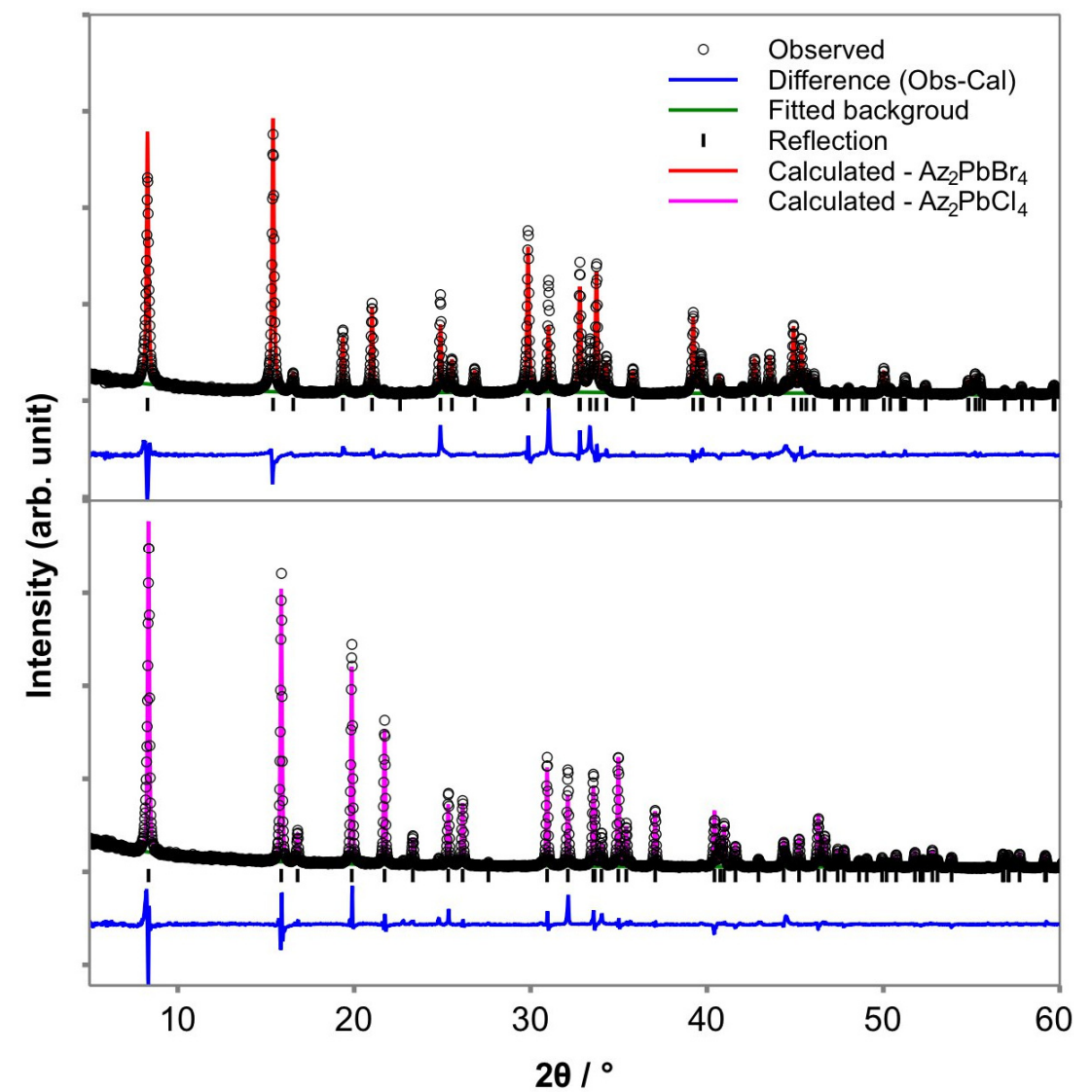

Figure 2. Rietveld refinement of PXRD data in $I 4 / m m m$ space group of $\mathrm{Az}_{2} \mathrm{PbX}_{4}, \mathrm{X}=\mathrm{Br}$ (top) and $\mathrm{Cl}$ (bottom) obtained from mechanosynthesis with observed data (open circles), calculated data (red line for $\mathrm{Br}$ and magenta line for $\mathrm{Cl}$ ), background (green lines), reflection positions (black bars) and difference plots (blue lines).

To study the mixed-halide solid solutions $\mathrm{Az}_{2} \mathrm{PbCl}_{x} \mathrm{Br}_{4-x}$, the lattice parameters of each mechanosynthesised composition were determined by Rietveld refinement of PXRD data. The cell volume of these R-P phases varies linearly as a function of the average anion radius, Figure $3 \mathrm{a}$ (the average anion radius was calculated using $r_{\mathrm{Br}}=196 \mathrm{pm}$ and $r_{\mathrm{Cl}}=181 \mathrm{pm}$ according to Shannon [22]). This linear variation is expected in accordance with Vegard's law. The lattice parameters $a$ and $c$, on the other hand, show a nonlinear relationship with the average anion radius (Figure $3 b$ ), which suggests anisotropic expansion/contraction along the $a$ - and $c$-axis. The larger expansion in $a$ is consistent with the increased $\mathrm{X}$ anion radius which affords a larger void for the $\mathrm{Az}^{+}$cation, resulting in less required expansion in the interlayer spacing. Based on the analysis using $\mathrm{Mn}^{2+}$ as a proxy for $\mathrm{Az}^{+}$we have no information regarding any orientation or dynamics of the $\mathrm{Az}^{+}$cation. 
a)

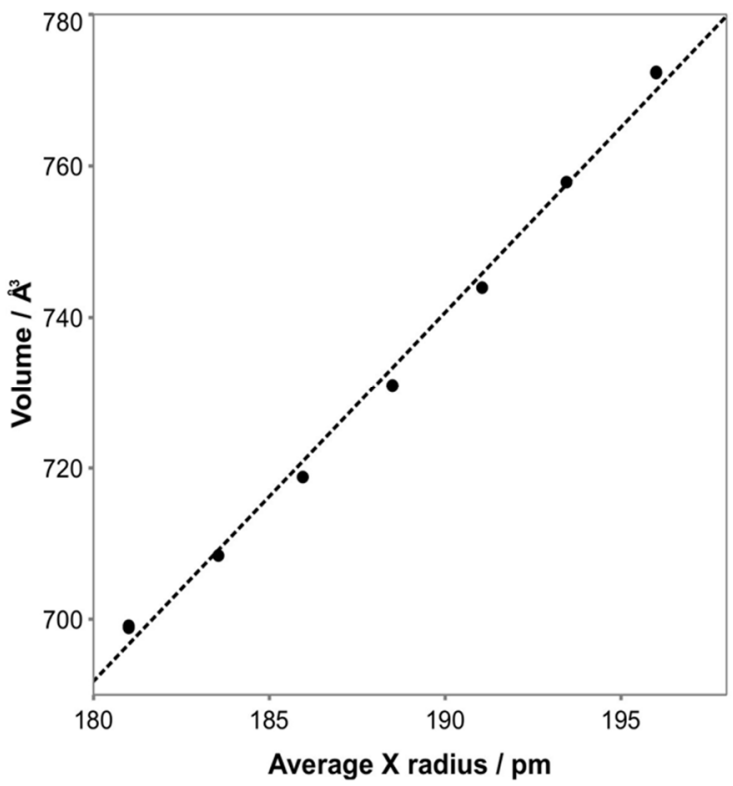

b)

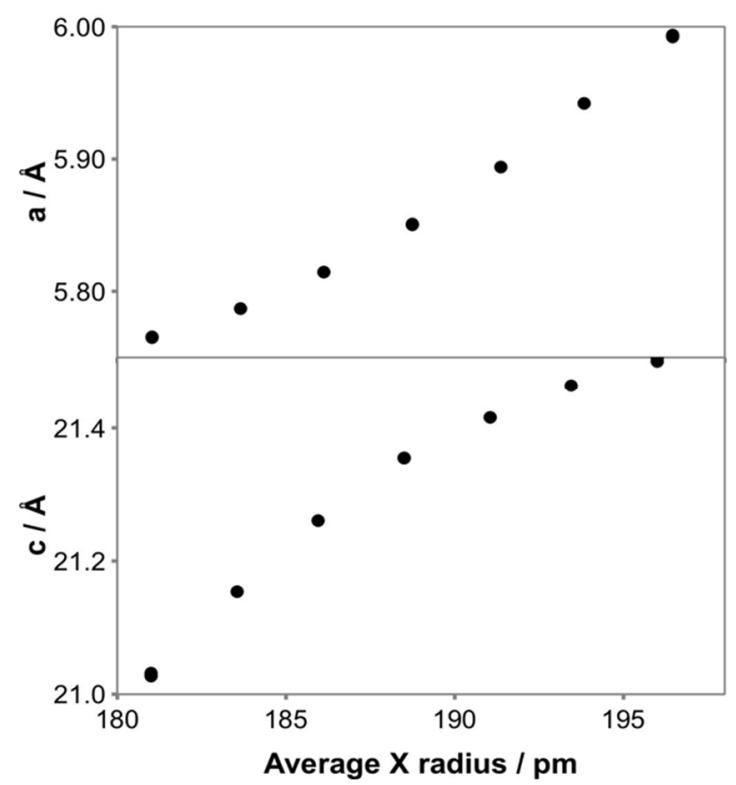

Figure 3. (a) Cell volume, (b) lattice parameters as a function of average halide anion radius for $n=1 \mathrm{R}-\mathrm{P}$ phases $\mathrm{Az}_{2} \mathrm{PbCl}_{x} \mathrm{Br}_{4-x}(0 \leq x \leq 4)$ as determined from Rietveld refinement of PXRD data.

One of the benefits of mechanosynthesis is that all materials are retained during the reaction, so the overall starting composition must be retained in the post-reaction compound(s). By inference, any product(s) must have the nominal starting composition. While we do not have direct compositional analysis, the PXRD results, Figure 2, clearly show that the product formed is entirely $n=1 \mathrm{R}-\mathrm{P}$ phase. It has been reported that the actual composition shows a good match with the nominal composition in the mechanosynthesis of OIHPs [23,24]. Thus, the halide compositions of $\mathrm{Az}_{2} \mathrm{PbCl}_{x} \mathrm{Br}_{4-x}$ are calculated according to the molar ratios of the raw materials (nominal composition).

The optical properties of $\mathrm{Az}_{2} \mathrm{PbCl}_{x} \mathrm{Br}_{4-x}(0 \leq x \leq 4)$ solid solutions were studied by absorption spectroscopy (Figure $4 \mathrm{a}$ ). The absorption onsets are systematically red-shifted from ca. $386 \mathrm{~nm}\left(\mathrm{Az}_{2} \mathrm{PbCl}_{4}\right)$ to ca. $457 \mathrm{~nm}\left(\mathrm{Az}_{2} \mathrm{PbBr}_{4}\right)$ with increasing average anion size (from $\mathrm{Cl}^{-}$to $\mathrm{Br}^{-}$). The bandgaps of $\mathrm{Az}_{2} \mathrm{PbCl}_{4}$ and $\mathrm{Az}_{2} \mathrm{PbBr}_{4}$ are calculated to be 3.43 and $2.81 \mathrm{eV}$, which are the same (within error) as the bandgap of the $6 \mathrm{H}$ hexagonal perovskite $\mathrm{AzPbCl}_{3}(3.43 \mathrm{eV})$ and $\mathrm{AzPbBr}_{3}(2.81 \mathrm{eV})$ [12]. However, unlike the linear variation in the $6 \mathrm{H} \mathrm{AzPbX}\left(\mathrm{X}^{-}=\mathrm{Cl}^{-}, \mathrm{Br}^{-}\right)$, the bandgap of layered $\mathrm{R}-\mathrm{P} \mathrm{Az} 2 \mathrm{PbX}_{4}(\mathrm{X}=\mathrm{Cl}, \mathrm{Br})$ shows a bowing with the average anion radius (Figure $4 \mathrm{~b}$ ). The bowing effect $[25,26]$ simply describes the deviation of the measured band gap in continuous solid solutions from the values expected by linear interpolation of the end member values. Band gap bowing is often fitted to a second-order polynomial to account for the divergence from linearity, with a bowing parameter $b$ as the binominal coefficient of the fitting Equation (1): [26]

$$
E_{g}(x)=(1-x) E_{g \mid(x=0)}+x E_{g \mid(x=1)}-b x(1-x)
$$




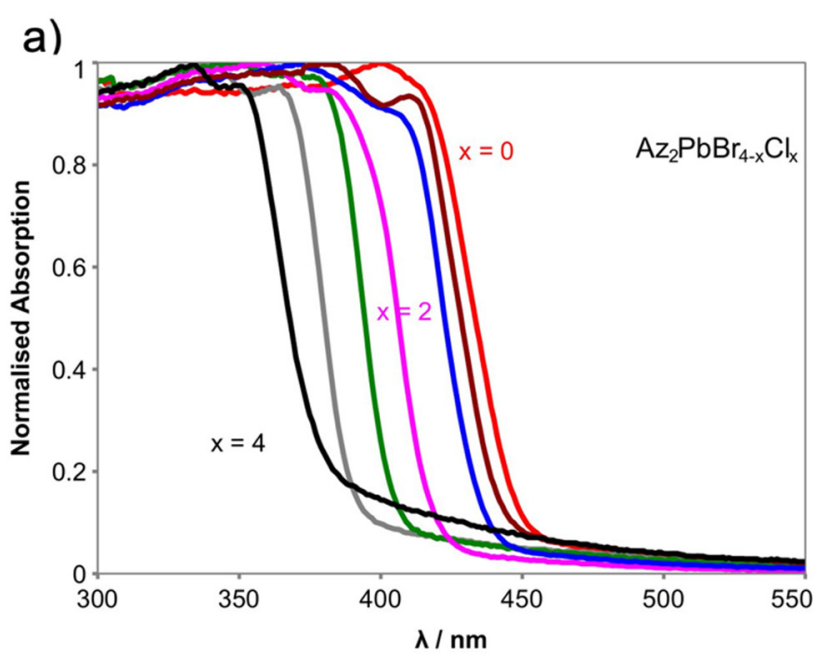

b)

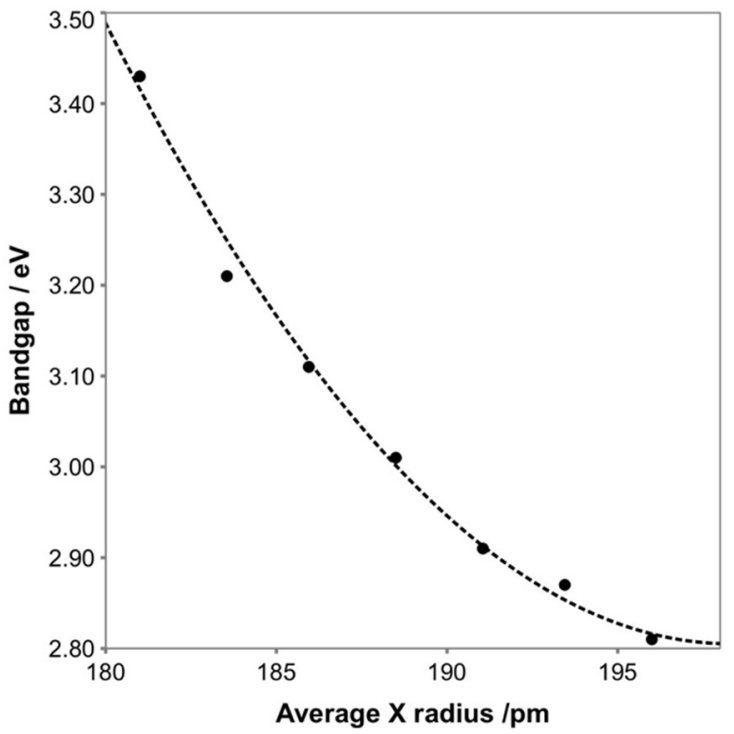

Figure 4. (a) Absorption spectra; (b) bandgap determination from the absorption spectra of samples $\mathrm{Az}_{2} \mathrm{PbCl}_{x} \mathrm{Br}_{4-x}$ with composition $0 \leq x \leq 4$ plotted as a function of average halide anion radius.

The bowing parameter, $b$, of the mechanosynthesised mixed halide layered $\mathrm{Az}_{2} \mathrm{PbCl}_{x} \mathrm{Br}_{4-x}(0 \leq x \leq 4)$ is 0.47 with a goodness-of-fit $\mathrm{R}^{2}$ value of 0.995 . The bowing parameter of mixed halide OIHPs are usually smaller, variously reported as $7 \times 10^{-4}$ to 0.33 for $\mathrm{MAPbBr}_{3-x} \mathrm{X}_{x}(\mathrm{X}=\mathrm{Cl}$ or I), $[27,28]$ compared to the bowing parameters $(0.4$ to 1.33) found for other mixed metal perovskite systems such as $\mathrm{MA}_{3}\left(\mathrm{Sb}_{1-x} \mathrm{Bi}_{x}\right) \mathrm{I}_{9}(0.4$ for $\mathrm{Bi}$ rich region and 1.3 for $\mathrm{Sb}$ rich region) and 1.06 for $\mathrm{MA}\left(\mathrm{Pb}_{1-x} \mathrm{Sn}_{x}\right) \mathrm{I}_{3}[25,26,29]$.

\section{Conclusions}

$n=1$ Ruddlesden-Popper (R-P) layered perovskite phases were successfully obtained by mechanosynthesis in the mixed halide solid solution $\mathrm{Az}_{2} \mathrm{PbCl}_{x} \mathrm{Br}_{4-x}$ with composition $0 \leq x \leq 4 . \mathrm{Az}_{2} \mathrm{PbX}_{4}(\mathrm{X}=\mathrm{Cl}, \mathrm{Br})$ was determined to be the conventional $\mathrm{R}-\mathrm{P} n=1\left(\mathrm{~K}_{2} \mathrm{NiF}_{4}\right)$ structure with a space group of $I 4 / \mathrm{mmm}$. A linear variation in unit cell volume as a function of anion average radius is observed. The band gap of the R-P phases $\mathrm{Az}_{2} \mathrm{PbCl}_{4}$ and $\mathrm{Az}_{2} \mathrm{PbBr}_{4}$ are determined to be 3.43 and $2.81 \mathrm{eV}$, which is the same (within error) as the bandgap of $6 \mathrm{H}$ hexagonal perovskite $\mathrm{AzPbCl}_{3}(3.43 \mathrm{eV})$ and $\mathrm{AzPbBr}_{3}(2.81 \mathrm{eV})$ [12]. A bowing effect with a bowing parameter of 0.47 is observed in the band gap-composition relationship of R-P layered mixed halide solid solutions, compared to the linear relationship observed in the $6 \mathrm{H}$ hexagonal perovskite.

Supplementary Materials: The following are available online. Supporting Information data include synthetic details of precipitation synthesis of $\mathrm{Az}_{2} \mathrm{PbX}_{4}(\mathrm{X}=\mathrm{Cl}, \mathrm{Br})$ (Figures S1 and S2) and synthesis of $\mathrm{Az}_{2} \mathrm{PbI}_{4}$ (Figure S3). Also, include selected crystallographic data obtained powder $\mathrm{X}$-ray diffraction of samples prepared by mechanosynthesis (Table S1).

Author Contributions: Conceptualization, J.T., E.Z.-C. and F.D.M.; methodology, J.T.; validation, J.T., E.Z.-C. and F.D.M.; formal analysis, J.T.; data curation, J.T.; writing-original draft preparation, J.T.; supervision, E.Z.-C. and F.D.M. All authors have read and agreed to the published version of the manuscript.

Funding: This research received no external funding. The publication of this work received support from the St Andrews Institutional Open Access Fund.

Institutional Review Board Statement: Not applicable.

Informed Consent Statement: Not applicable.

Data Availability Statement: The research data supporting this publication can be accessed at https:/ / doi.org/10.17630/fd5aab9b-fced-4926-afee-5eb56e2e6a5e (accessed on 15 October 2021). 
Acknowledgments: We thank the Chinese Scholarship Council for support to JT (CSC No. 20160378 0020).

Conflicts of Interest: The authors declare no conflict of interest.

Sample Availability: Samples of the $\mathrm{Az}_{2} \mathrm{PbCl}_{x} \mathrm{Br}_{4-x}$ with composition $0 \leq x \leq 4$ are available from the authors.

\section{References}

1. Lichtenberg, F.; Herrnberger, A.; Wiedenmann, K. Synthesis, structural, magnetic and transport properties of layered perovskiterelated titanates, niobates and tantalates of the type $\mathrm{A}_{n} \mathrm{~B}_{n} \mathrm{O}_{3 n+2}, \mathrm{~A}^{\prime} \mathrm{A}_{k-1} \mathrm{~B}_{k} \mathrm{O}_{3 k+1}$ and $\mathrm{A}_{m} \mathrm{~B}_{m-1} \mathrm{O}_{3 m}$. Prog. Solid State Chem. 2008, 36, 253-387. [CrossRef]

2. Aleksandrov, K.S.; Beznosikov, V.V. Hierarchies of perovskite-like crystals (Review). Phys. Solid State 1997, 39, 695-715. [CrossRef]

3. Balz, D.; Plieth, K. Die Struktur des Kaliumnickelfluorids, $\mathrm{K}_{2}$ NiF. Z. Elektrochem. Ber. Bunsenges. Phys. Chem. 1955, 59, 545-551. [CrossRef]

4. Ruddlesden, S.N.; Popper, P. New compounds of the $\mathrm{K}_{2} \mathrm{NiF}_{4}$ type. Acta Crystallogr. 1957, 10, 538-539. [CrossRef]

5. Stoumpos, C.C.; Cao, D.H.; Clark, D.J.; Young, J.; Rondinelli, J.M.; Jang, J.I.; Hupp, J.T.; Kanatzidis, M.G. Ruddlesden-Popper hybrid lead iodide perovskite 2D homologous semiconductors. Chem. Mater. 2016, 28, 2852-2867. [CrossRef]

6. Du, K.Z.; Tu, Q.; Zhang, X.; Han, Q.; Liu, J.; Zauscher, S.; Mitzi, D.B. Two-dimensional lead(II) halide-based hybrid perovskites templated by acene alkylamines: Crystal structures, optical properties, and piezoelectricity. Inorg. Chem. 2017, 56, 9291-9302. [CrossRef]

7. Mitzi, D.B. A layered solution crystal growth technique and the crystal structure of $\left(\mathrm{C}_{6} \mathrm{H}_{5} \mathrm{C}_{2} \mathrm{H}_{4} \mathrm{NH}_{3}\right)_{2} \mathrm{PbCl}_{4}$. J. Solid State Chem. 1999, 145, 694-704. [CrossRef]

8. Spanopoulos, I.; Hadar, I.; Ke, W.; Tu, Q.; Chen, M.; Tsai, H.; He, Y.; Shekhawat, G.; Dravid, V.P.; Wasielewski, M.R.; et al. Uniaxial expansion of the 2D Ruddlesden-Popper perovskite family for improved environmental stability. J. Am. Chem. Soc. 2019, 141, 5518-5534. [CrossRef]

9. Tsai, H.; Nie, W.; Blancon, J.C.; Stoumpos, C.C.; Asadpour, R.; Harutyunyan, B.; Neukirch, A.J.; Verduzco, R.; Crochet, J.J.; Tretiak, S.; et al. High-efficiency two-dimensional Ruddlesden-Popper perovskite solar cells. Nature 2016, 536, 312-317. [CrossRef] [PubMed]

10. Leng, K.; Abdelwahab, I.; Verzhbitskiy, I.; Telychko, M.; Chu, L.; Fu, W.; Chi, X.; Guo, N.; Chen, Z.; Chen, Z.; et al. Molecularly thin two-dimensional hybrid perovskites with tunable optoelectronic properties due to reversible surface relaxation. Nat. Mater. 2018, 17, 908-914. [CrossRef]

11. Ren, H.; Yu, S.; Chao, L.; Xia, Y.; Sun, Y.; Zuo, S.; Li, F.; Niu, T.; Yang, Y.; Ju, H.; et al. Efficient and stable Ruddlesden-Popper perovskite solar cell with tailored interlayer molecular interaction. Nat. Photonics 2020, 14, 154-163. [CrossRef]

12. Tian, J.; Cordes, D.B.; Slawin, A.M.Z.; Zysman-Colman, E.; Morrison, F.D. Progressive polytypism and bandgap tuning in azetidinium lead halide perovskites. Inorg. Chem. 2021, 60, 12247-12254. [CrossRef] [PubMed]

13. Tian, J.; Zysman-Colman, E.; Morrison, F.D. Compositional variation in hybrid organic-inorganic lead halide perovskites: Kinetically versus thermodynamically controlled synthesis. Chem. Mater. 2021, 33, 3650-3659. [CrossRef]

14. Kieslich, G.; Sun, S.; Cheetham, A.K.; Cheetham, T.; Gregor, K.; Shijing, S.; Anthony, K.C. Solid-state principles applied to organic-inorganic perovskites: New tricks for an old dog. Chem. Sci. 2014, 5, 4712-4715. [CrossRef]

15. Levchuk, I.; Osvet, A.; Tang, X.; Brandl, M.; Perea, J.D.; Hoegl, F.; Matt, G.J.; Hock, R.; Batentschuk, M.; Brabec, C.J. Brightly luminescent and color-tunable formamidinium lead halide perovskite $\mathrm{FAPbX}_{3}(\mathrm{X}=\mathrm{Cl}, \mathrm{Br}, \mathrm{I})$ colloidal nanocrystals. Nano Lett. 2017, 17, 2765-2770. [CrossRef] [PubMed]

16. Cao, M.; Tian, J.; Cai, Z.; Peng, L.; Yang, L.; Wei, D. Perovskite heterojunction based on $\mathrm{CH}_{3} \mathrm{NH}_{3} \mathrm{PbBr}_{3}$ single crystal for high-sensitive self-powered photodetector. Appl. Phys. Lett. 2016, 109, 233303. [CrossRef]

17. Tian, J.; Cordes, D.B.; Quarti, C.; Beljonne, D.; Slawin, A.M.Z.; Zysman-Colman, E.; Morrison, F.D. Stable 6H organic-inorganic hybrid lead perovskite and competitive formation of $6 \mathrm{H}$ and $3 \mathrm{C}$ perovskite structure with mixed A cations. ACS Appl. Energy Mater. 2019, 2, 5427-5437. [CrossRef]

18. Larson, A.C.; Von Dreele, R.B. General Structure Analysis System (GSAS); Los Alamos National Laboratory: Carlsbad, NM, USA, 2004; pp. 86-748.

19. Yu, J.C.; Kim, D.B.; Jung, E.D.; Lee, B.R.; Song, M.H. High-performance perovskite light-emitting diodes via morphological control of perovskite films. Nanoscale 2016, 8, 7036-7042. [CrossRef]

20. Ganguli, D. Cationic radius ratio and formation of $\mathrm{K}_{2} \mathrm{NiF}_{4}$-type compounds. J. Solid State Chem. 1979, 30, 353-356. [CrossRef]

21. Panetta, R.; Righini, G.; Colapietro, M.; Barba, L.; Tedeschi, D.; Polimeni, A.; Ciccioli, A.; Latini, A. Azetidinium lead iodide: Synthesis, structural and physico-chemical characterization. J. Mater. Chem. A 2018, 6, 10135-10148. [CrossRef]

22. Shannon, R.D. Revised effective ionic radii and systematic studies of interatomic distances in halides and chalcogenides. Acta Crystallogr. Sect. A 1976, 32, 751-767. [CrossRef]

23. Pal, P.; Saha, S.; Banik, A.; Sarkar, A.; Biswas, K. All-solid-state mechanochemical synthesis and post-synthetic transformation of inorganic perovskite-type halides. Chem. Eur. J. 2018, 24, 1811-1815. [CrossRef] [PubMed] 
24. Saski, M.; Prochowicz, D.; Marynowski, W.; Lewiński, J. Mechanosynthesis, optical, and morphological properties of MA, FA, $\mathrm{CsSnX}_{3}(\mathrm{X}=\mathrm{I}, \mathrm{Br})$ and phase-pure mixed-halide $\mathrm{MASnI}_{x} \mathrm{Br}_{3-x}$ perovskites. Eur. J. Inorg. Chem. 2019, 2019, 2680-2684. [CrossRef]

25. Lee, S.; Levi, R.D.; Qu, W.; Lee, S.C.; Randall, C.A. Band-gap nonlinearity in perovskite structured solid solutions. J. Appl. Phys. 2010, 107, 023523. [CrossRef]

26. Chatterjee, S.; Payne, J.; Irvine, J.T.S.; Pal, A.J. Bandgap bowing in a zero-dimensional hybrid halide perovskite derivative: Spin-orbit coupling: Versus lattice strain. J. Mater. Chem. A 2020, 8, 4416-4427. [CrossRef]

27. Noh, J.H.; Im, S.H.; Heo, J.H.; Mandal, T.N.; Seok, S. Il Chemical management for colorful, efficient, and stable inorganic-organic hybrid nanostructured solar cells. Nano Lett. 2013, 13, 1764-1769. [CrossRef]

28. Wang, W.; Su, J.; Zhang, L.; Lei, Y.; Wang, D.; Lu, D.; Bai, Y. Growth of mixed-halide perovskite single crystals. CrystEngComm 2018, 20, 1635-1643. [CrossRef]

29. Hu, Z.; Lin, Z.; Su, J.; Zhang, J.; Chang, J.; Hao, Y. A review on energy band-gap engineering for perovskite photovoltaics. Sol. RRL 2019, 3, 1900304. [CrossRef] 